\title{
A randomized trial of phenylephrine infusion versus bolus dosing for nausea and vomiting during Cesarean delivery in obese women Une étude randomisée comparant une perfusion versus un bolus de phényléphrine chez des femmes obèses pour traiter les nausées et vomissements pendant un accouchement par césarienne
}

\author{
Ronald B. George, MD, FRCPC (D) Dolores M. McKeen, MD, MSc, FRCPC • \\ Jennifer E. Dominguez, MD, MHS • Terrence K. Allen, MB, BS, MHS, FRCA • \\ Patricia A. Doyle, MD, FRCPC • Ashraf S. Habib, MB, BCh, MSc, MHS, FRCA \\ Received: 3 May 2017/Revised: 31 October 2017/Accepted: 1 November 2017 / Published online: 5 December 2017 \\ (C) Canadian Anesthesiologists' Society 2017
}

\begin{abstract}
Purpose Hypotension is common after spinal anesthesia for Cesarean delivery. It is associated with nausea, vomiting, and fetal acidosis. Previous research on phenylephrine excluded obese subjects. We compared the incidence of intraoperative nausea and vomiting (IONV) in obese patients who received a prophylactic phenylephrine infusion vs those who received bolus dosing for the treatment of spinal-induced hypotension.

Methods In this multicentre, double-blinded randomized controlled trial, 160 obese women undergoing elective Cesarean delivery under spinal anesthesia were randomized to receive a prophylactic phenylephrine infusion initiated at $50 \mu \mathrm{g} \cdot \mathrm{min}^{-1}$ (and titrated according to a predefined algorithm) or $100 \mu \mathrm{g}$ phenylephrine boluses to treat hypotension. Maternal systolic blood pressure was
\end{abstract}

This article is accompanied by an editorial. Please see Can J Anesth 2018; 65: this issue.

Electronic supplementary material The online version of this article (https://doi.org/10.1007/s12630-017-1034-6) contains supplementary material, which is available to authorized users.

R. B. George, MD, FRCPC ( $)$ · D. M. McKeen, MD, MSc, FRCPC - P. A. Doyle, MD, FRCPC

Department of Women's \& Obstetric Anesthesia, IWK Health

Centre, Dalhousie University, 5850/5980 University Avenue,

P.O. Box 9700, Halifax, NS B3K 6R8, Canada

e-mail: rbgeorge@dal.ca

J. E. Dominguez, MD, MHS - T. K. Allen, MB, BS, MHS, FRCA · A. S. Habib, MB, BCh, MSc, MHS, FRCA Department of Anesthesiology, Duke University Medical Center, Durham, NC, USA maintained within $20 \%$ of baseline. The primary study outcome was the incidence of IONV.

Results Intraoperative nausea and vomiting were significantly reduced in the infusion group compared to the bolus group $(46 \%$ vs $75 \%$, respectively; relative risk [RR], 0.61; 95\% confidence interval [CI], 0.47 to $0.80 ; \mathrm{P}<$ 0.001). This was associated with significantly reduced need for intraoperative rescue antiemetics $(26 \%$ vs $42 \%$, respectively; $R R, 0.62 ; 95 \% C I, 0.40$ to $0.97 ; P=0.04$ ), but no difference in the incidence of vomiting. Postoperative vomiting at two hours was reduced in the infusion group (11\% vs 25\%; RR, 0.44; 95\% CI, 0.21 to 0.90; $P=0.02)$; however, there were no differences in the incidence or severity of postoperative nausea, need for rescue antiemetics at two hours and $24 \mathrm{hr}$, or the incidence of postoperative vomiting at $24 \mathrm{hr}$.

Conclusion In obese women undergoing Cesarean delivery with spinal anesthesia, prophylactic phenylephrine infusion was associated with less intraoperative nausea, less need for rescue antiemetics, and reduced early postoperative vomiting.

Trial registration $w w w$.clinicaltrials.gov $\quad$ (NCT014817 40). Registered 22 July 2011.

Résumé

Objectif L'hypotension est fréquente après une rachianesthésie pour césarienne. Elle est associée à des nausées et vomissements ainsi qu'à une acidose fotale. Les recherches antérieures utilisant la phényléphrine excluaient les patientes obèses. Nous avons comparé l'incidence de nausées et vomissements peropératoires chez les patientes obèses ayant reçu une perfusion de 
phényléphrine en prophylaxie à celles ayant reçu un bolus pour traiter l'hypotension induite par la rachianesthésie.

Méthode Dans cette étude randomisée contrôlée multicentrique à double insu, 160 patientes obèses subissant un accouchement par césarienne non urgent sous rachianesthésie ont été randomisées à recevoir une perfusion prophylactique de phényléphrine à un taux de 50 $\mu \mathrm{g} \cdot \mathrm{min}^{-1}$ (et titrée selon un algorithme prédéfini) ou des bolus de $100 \mu g$ de phényléphrine pour traiter l'hypotension. La tension artérielle systolique maternelle a été maintenue à l'intérieur d'une marge de $20 \%$ de sa valeur initiale. Le critère d'évaluation principal de l'étude était l'incidence de nausées et vomissements peropératoires.

Résultats Les nausées et vomissements peropératoires étaient significativement réduits dans le groupe perfusion par rapport au groupe bolus $(46 \%$ vs $75 \%$, respectivement; risque relatif $[R R], 0,61$; intervalle de confiance [IC] $95 \%, 0,47$ à 0,80; $P<0,001)$. Cette réduction a été associée à des besoins significativement réduits en antiémétiques (26\% vs $42 \%$, respectivement; $R R, 0,62 ;$ IC $95 \%, 0,40$ à 0,97; $P=0,04)$, mais à aucune différence dans l'incidence des vomissements. Les vomissements postopératoires à deux heures étaient moins importants dans le groupe perfusion $(11 \%$ vs $25 \%$; RR, 0,44; IC $95 \%, 0,21$ à 0,90; $P=0,02$ ); toutefois, aucune différence n'a été observée dans l'incidence ou la gravité des nausées postopératoires, dans le besoin d'antiémétiques à deux heures et $24 h$, ou dans l'incidence des vomissements postopératoires à $24 \mathrm{~h}$.

Conclusion Chez les femmes obèses subissant une césarienne sous rachianesthésie, une perfusion prophylactique de phényléphrine a été associée à une diminution des nausées peropératoires avec une réduction des besoins d'antiémétiques, ainsi qu'à une réduction des vomissements postopératoires précoces.

\section{Enregistrement de l'étude www.clinicaltrials.gov} (NCT01481740). Enregistrée le 22 juillet 2011.

Spinal anesthesia is safe and effective; it is currently the anesthetic technique of choice for elective Cesarean delivery (CD). However, one of the common complications of this technique is hypotension with a reported incidence of up to $74 \%$. $^{1}$ Maternal hypotension is one of the primary causes of intraoperative nausea and/or vomiting (IONV); this symptom is thought to be caused by cerebral and gut hypoperfusion that stimulate the vomiting centre in the brainstem and cause serotonin release, respectively. 2,3
While bolus dosing of phenylephrine effectively treats maternal hypotension, it does not prevent intraoperative maternal nausea, which may be associated with established hypotension, and this may adversely affect patient satisfaction. ${ }^{4,5}$ In a previous study, prophylactic phenylephrine infusions reduced the incidence of hypotension from $88-23 \%$ with a concomitant reduction in maternal nausea and vomiting from $21 \%$ to $4 \%$ when compared to treatment of established hypotension with boluses of phenylephrine. ${ }^{4}$ However, the difference in IONV was not statistically significant, since the study was not powered for this outcome. Patients $<50 \mathrm{~kg}$ and $>100$ $\mathrm{kg}$ were excluded from study enrolment. The median [interquartile range (IQR)] weight of patients in this study's intervention group was 67 [60-75] kg. The other study using a variable rate prophylactic phenylephrine infusion in parturients with a mean (standard deviation [SD]) weight of 79 (10) $\mathrm{kg}$ also reported a significant reduction in the incidence of hypotension and IONV compared to rescue phenylephrine boluses. ${ }^{5}$

Recent data from the Centers for Disease Control estimate that approximately $30-35 \%$ of pre-menopausal women in the United States are obese (body mass index $[\mathrm{BMI}] \geq 30 \mathrm{~kg} \cdot \mathrm{m}^{-2}$ ). ${ }^{6}$ Both pregnancy and obesity have profound effects on the mother's physiology, which may alter the cardiovascular response to both spinal anesthetics $^{7-9}$ and vasopressor therapy., ${ }^{9,10}$ Pregnancy is associated with a significant increase in both cardiac output and blood volume, which are further increased by obesity. ${ }^{5,11,12}$ Although pregnancy is usually associated with a significant reduction in afterload, this may be less pronounced in the obese population because of increased peripheral resistance and greater conduit artery stiffness. ${ }^{9,12,13}$ Maternal BMI itself may impact the pharmacodynamic effects of phenylephrine dosing when administered as a bolus or a continuous infusion. Obese women may also have different anesthetic requirements compared to their non-obese parturient counterparts. Obese women have reduced lumbar cerebrospinal fluid volume, which can be inversely related to cephalad spread of local anesthetics. ${ }^{14}$ Carvalho et al. ${ }^{7}$ and Lee et al. ${ }^{15}$ found no association with BMI and the height of spinal anesthesia for obese women undergoing a CD. However, the study sizes are small and use methods that assume large sample properties. They also require extrapolation of the upper dose range, and precision estimates were wide for the important effective dose required for the desired effect in $95 \%$ of the population (effective dose [ED] 95). ${ }^{8}$ A recent retrospective study also found a higher level of spinal block with increased vasopressor requirements in obese parturients with BMI $>50 \mathrm{~kg} \cdot \mathrm{m}^{-216}$ compared to those with lower BMI. ${ }^{17}$ Therefore, without more prospective 
controlled studies, it is still debated whether the local anesthetic dose should be further reduced in obese women.

Most previous research regarding the use of phenylephrine infusions compared to bolus dosing did not include obese subjects ${ }^{4,5}$ or did not have IONV as a primary endpoint of the study. ${ }^{4,18}$ The primary aim of this multicentre, randomized, double-blinded, placebocontrolled study was to compare the incidence of IONV in two groups of obese parturients undergoing elective $\mathrm{CD}$; one group received a prophylactic phenylephrine infusion, while the other group received phenylephrine boluses for the treatment of established hypotension related to a standard spinal anesthetic. We hypothesized that the incidence of IONV would be significantly reduced with the use of a prophylactic phenylephrine infusion.

\section{Methods}

This was a multicentre, double-blinded, randomized, placebo-controlled trial. This study was performed at Duke University Medical Center, Durham, NC, USA, and at the IWK Health Centre, Halifax, Nova Scotia, Canada, between March 2011 and October 2014. Research ethics board approval was obtained from both institutions. The trial was registered at www.clinicaltrials.gov (NCT01481740). Adult (age $\geq 18$ yr old), American Society of Anesthesiologists (ASA) physical status II-III, non-labouring, obese (current BMI $>35-55 \mathrm{~kg} \cdot \mathrm{m}^{-2}$ ) females, with singleton gestation, $\geq 36$ weeks, undergoing non-emergent CD under spinal anesthesia were recruited. Exclusion criteria included the following: height $<152 \mathrm{~cm}$ ( 5 feet, 0 inches); antiemetic drug use in the $24 \mathrm{hr}$ prior to $\mathrm{CD}$; mid-humeral arm circumference $>46 \mathrm{~cm}$; allergy to phenylephrine or any other standardized medication used in the study; hypertensive diseases of pregnancy (gestational hypertension, preeclampsia); chronic hypertension on antihypertensive treatment; severe cardiac disease in pregnancy with marked functional limitations; patients taking monoamine oxidase inhibitors or tricyclic antidepressants; or any other physical or psychiatric condition that may have impaired the patients' ability to cooperate with data collection. Participants were withdrawn from the study if they did not receive the allocated intervention, i.e.,

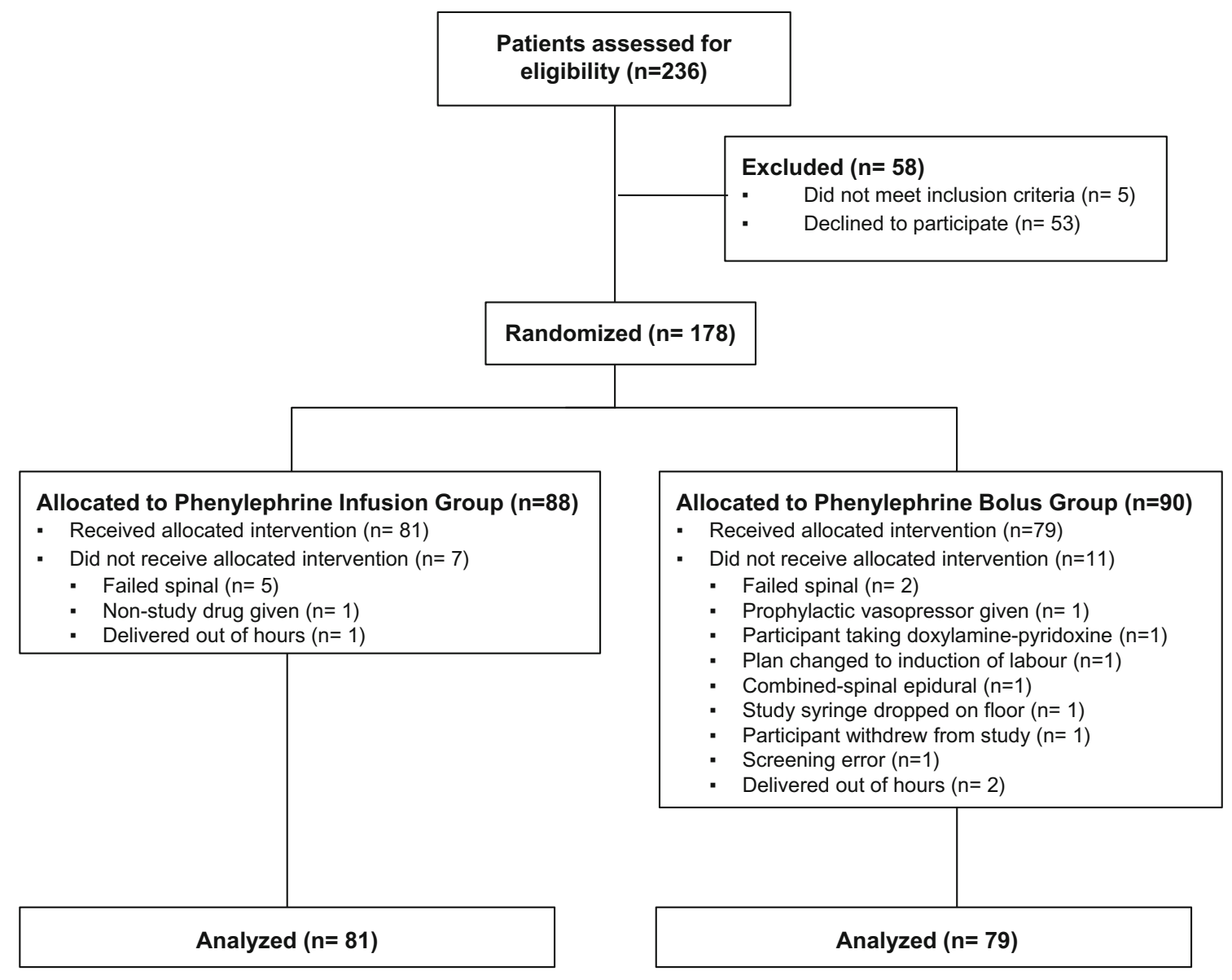

Figure Flow diagram of patient enrolment, allocation, and analysis 
failed spinal, or other significant deviation from the study protocol.

After obtaining written informed consent and before entering the operating room, participants underwent noninvasive blood pressure measurements three times (every two minutes) in the supine position with left uterine displacement achieved by a wedge under their right hip. The mean of the three systolic blood pressure (SBP) readings was deemed the baseline SBP. Hypotension was defined as the higher blood pressure of either SBP $<80 \%$ of baseline or $<90 \mathrm{mmHg}$. All women received antacid prophylaxis with $30 \mathrm{~mL}$ sodium citrate prior to surgery. Patients were asked about possible risk factors for postoperative nausea and vomiting (PONV).

Obese participants were randomized using computergenerated random sequence to receive a prophylactic phenylephrine infusion starting at $50 \mu \mathrm{g} \cdot \mathrm{min}^{-1}$ or a 100 $\mu \mathrm{g}$ phenylephrine bolus to treat hypotension. Randomization was stratified by site to ensure an equal number of patients per group at each site, with anticipated unequal recruitment of patients per site due to the differing institutional annual delivery rates. Once the patient had consented, an opaque sealed randomization envelope was opened by an anesthesiologist not involved in the study, who then prepared two blinded syringes per patient labelled "Syringe A" and "Syringe B". Only one syringe per patient contained phenylephrine, the other normal saline (NS) placebo. Syringe A was a $60-\mathrm{mL}$ syringe (phenylephrine $100 \mu \mathrm{g} \mathrm{mL} \mathrm{m}^{-1}$ or NS) for the infusion and syringe B was a 20-mL syringe (phenylephrine $100 \mu \mathrm{g}$ $\mathrm{mL}^{-1}$ or NS) for bolus administration.

In the operating room with routine monitors applied and vascular access established, all women were positioned seated and were administered a spinal anesthetic between L3 and L5 intervertebral spaces of hyperbaric $0.75 \%$ bupivacaine $12 \mathrm{mg}$, fentanyl $15 \mu \mathrm{g}$, and preservative-free morphine $150 \mu \mathrm{g}$. Patients were immediately positioned supine on a tilted table to facilitate left uterine displacement. An infusion of Lactated Ringer's (LR) solution was started as a bolus at the time that the intrathecal drugs were administered; the aim was to administer $2 \mathrm{~L}$ of LR solution prior to delivery followed by a maintenance fluid regimen. Block height was determined by pinprick at five and ten minutes after spinal administration. All participants within the study underwent a Pfannenstiel incision during $\mathrm{CD}$ as per the standards at the IWK Health Centre. Postoperatively all women received a standardized analgesic regimen that included acetaminophen and naproxen initiated after admission to the postanesthesia care unit and oral oxycodone 5-10 mg prn for additional pain.

The contents of Syringe A were administered as an infusion with an initial rate of $30 \mathrm{~mL} \cdot \mathrm{hr}^{-1}$ immediately after the placement of the spinal block. The infusion rate was adjusted in response to changes in blood pressure according to a treatment algorithm (Appendix; available as Electronic Supplementary Material) based on non-invasive blood pressure readings. The goal of the algorithm was to keep maternal SBP within $20 \%$ of baseline. As per algorithm, if the patient experienced hypotension, the provider doubled the infusion rate of Syringe $\mathrm{A}$ and administered a 1-mL bolus from Syringe B. That is, hypotension was treated by increasing the phenylephrine infusion from $50 \mu \mathrm{g} \mathrm{min} \mathrm{m}^{-1}$ to $100 \mu \mathrm{g} \mathrm{min} \mathrm{m}^{-1}$ or by administering a phenylephrine bolus of $100 \mu \mathrm{g}$. If bradycardia (defined as a heart rate $<50$ beats $\min ^{-1}$ ) occurred with hypotension, glycopyrrolate $0.2 \mathrm{mg} i v$ was administered.

Oxytocin $5 \mathrm{U}$ intravenous bolus was given rapidly after delivery of the neonate followed by an oxytocin infusion of 12.5 - $25 \mathrm{U} \cdot \mathrm{hr}^{-1}$ (to a total dose of $25 \mathrm{U}$ as was standard practice) until the end of the surgery. Intraoperative nausea and vomiting not related to a BP measurement $<80 \%$ of baseline or $<90 \mathrm{mmHg}$ were treated with ondansetron 4 $\mathrm{mg} i v$. Postoperative nausea and vomiting, pruritus, and postoperative analgesia management was standardized as per institutional practices.

In the operating room, research personnel blinded to the randomization assignment recorded the following: noninvasive blood pressure readings (every one minute for the first $15 \mathrm{~min}$ following spinal anesthetic, then every $2.5 \mathrm{~min}$ until delivery, then every one minute for ten minutes following delivery); heart rate; intraoperative nausea scores; occurrence and number of vomiting episodes; and the need for rescue antiemetics. A nausea score was elicited from all subjects and was inclusive of the time in between each assessment, every five minutes for the first ten minutes after spinal anesthesia, and then every ten minutes until ten minutes post-delivery. Nausea was defined as feeling the urge to vomit, and nausea scores were collected using an 11-point verbal rating scale $(0=$ no nausea, $10=$ worst possible nausea). Intraoperative nausea and vomiting occurring immediately before or after a $20 \%$ reduction in baseline $\mathrm{SBP}$ or $\mathrm{SBP}<90 \mathrm{mmHg}$ was recorded as "hypotension-associated IONV". Research staff collected the postoperative nausea, vomiting, and antiemetic therapy data at two and $24 \mathrm{hr}$ after surgery. At the end of surgery, patients were asked to rate their worst pruritus score $(0=$ no pruritus, $10=$ worst possible pruritus $)$ and their satisfaction with IONV control ( 1 = very satisfied, 2 = somewhat satisfied, $3=$ neither satisfied nor dissatisfied, $4=$ somewhat dissatisfied, $5=$ very dissatisfied). The duration of surgery, volume of intravenous fluids administered, estimated blood loss, total phenylephrine used, and exteriorization of the uterus were recorded. Postoperatively, nausea scores, number of 
vomiting episodes, and need for rescue antiemetic therapy were self-reported from $0-2$ and 2-24 hr after surgery (time $0=$ operating room exit).

The primary study outcome was the incidence of IONV. Secondary study outcomes included the following: incidence of hypotension induced IONV (defined as IONV that occurred immediately before or after a $20 \%$ or more reduction in SBP or SBP $<90 \mathrm{mmHg}$ ); need for rescue antiemetics; incidence of PONV; maternal satisfaction with management of nausea and vomiting; incidence of pre- and post-delivery hypotension (SBP < $80 \%$ of baseline or $<90 \mathrm{mmHg}$ ); incidence of reactive hypertension (SBP $>120 \%$ baseline); and number of physician interventions needed to maintain maternal SBP within $20 \%$ of baseline (increase/decrease/stop infusion, administration of boluses, administration of glycopyrrolate).

\section{Statistical analysis}

Descriptive statistics are expressed as mean \pm standard deviation. The Student's $t$ test was used for comparison of continuous, normally distributed data. Data distributed non-normally are presented as median [IQR] and analyzed using the Mann-Whitney U test. Categorical data were analyzed using the $\chi^{2}$ test. SPSS 21.0 software (IBM Corp. Armonk, NY, USA) was used for statistical analysis with $P$ $<0.05$ considered statistically significant.

Data from a previous study reported an incidence of IONV of $40 \%$ when using boluses of phenylephrine for the treatment of established hypotension. ${ }^{18}$ Based on these data, we calculated that a sample size of 81 subjects per group would have an $80 \%$ power to detect a reduction in the incidence of IONV from $40 \%$ to $20 \%$ at alpha $=0.05$.

\section{Results}

One hundred seventy-eight patients were enrolled in this study. Of those, 160 parturients completed the study and were included in the analysis (Figure). The mean (SD) BMI of participants was 41 (4) $\mathrm{kg} \cdot \mathrm{m}^{-2}$. There were no differences in patient demographics, risk factors for PONV, block height, duration of surgery, volume of fluids administered, estimated blood loss, or exteriorization of the uterus between groups (Table 1). No participants required additional uterotonics in addition to the oxytocin protocol outlined in the methods.

Of the 79 participants in the bolus group, 59 experienced IONV (75\%). This incidence was significantly greater than the $46 \%$ (37/81) who experienced IONV in the infusion group (relative risk [RR], 0.61; 95\% confidence interval
Table 1 Patient characteristics and intraoperative variables

\begin{tabular}{lll}
\hline & $\begin{array}{l}\text { Infusion }(n= \\
81)\end{array}$ & Bolus $(n=$ \\
\hline Age (yr) & $31(5)$ & $32(6)$ \\
Body mass index $\left(\mathrm{kg} \cdot \mathrm{m}^{-2}\right)$ & $40.8(4.2)$ & $41.1(4.5)$ \\
Body mass index $>45 \mathrm{~kg} \cdot \mathrm{m}^{-2}$ & $16(20 \%)$ & $12(15 \%)$ \\
Gestational age (weeks) & $39(1)$ & $39(1)$ \\
Gravidity & $3[2-4]$ & $2[2-4]$ \\
Parity & $1[1-2]$ & $1[1-2]$ \\
History of IONV & $19 / 60(32 \%)$ & $28 / 67(42 \%)$ \\
History of PONV & $23 / 74(31 \%)$ & $27 / 75(36 \%)$ \\
History of motion sickness & $23(28 \%)$ & $26(33 \%)$ \\
Morning sickness & $65(80 \%)$ & $58 / 78(74 \%)$ \\
Smoker & $13(16 \%)$ & $13(16 \%)$ \\
Block height at 10 min (thoracic & $4[3-4]$ & $4[3-4]$ \\
$\quad$ dermatome) & & $57(22)$ \\
Duration of surgery (min) & $55(21)$ & $62(78 \%)$ \\
Repeat Cesarean delivery & $71(88 \%)$ & $2128(535)$ \\
Volume of lactated ringer & $1995(460)$ & \\
$\quad$ administered (mL) & $702(186)$ & $743(268)$ \\
Estimated blood loss (mL) & $2116(1082)$ & $374(357)$ \\
Total phenylephrine administered $(\mu \mathrm{g})$ & $36(45 \%)$ \\
Uterus exteriorized & $33(41 \%)$ & \\
\hline
\end{tabular}

IONV = intraoperative nausea and/ or vomiting; PONV = postoperative nausea and/or vomiting. Data are mean (standard deviation), median [interquartile range], $n(\%)$ or $n / \mathrm{N}(\%)$

[CI], 0.47 to $0.80 ; P<0.001)$. However, there was no difference in the incidence of intraoperative vomiting between the two groups (Table 2). The incidence of hypotension-associated IONV was also significantly lower in the infusion group compared to the bolus group ( $13 \%$ vs $54 \%$, respectively; RR, 0.25 ; $95 \%$ CI, 0.11 to 0.58 ; $P<0.001)$. Subjects in the bolus group needed rescue antiemetics more frequently (RR, $0.62 ; 95 \% \mathrm{CI}, 0.40$ to $0.97 ; P=0.04)$ and had worse intraoperative nausea scores (Table 2). There were no significant differences in the worst pruritus score or patient satisfaction scores between the two groups. At two and $24 \mathrm{hr}$ postoperatively, there were no significant differences in the incidence of nausea, the worst nausea score, or need for rescue antiemetics. However, participants in the bolus group experienced significantly more vomiting two hours postoperatively compared to the infusion group; there was no difference at $24 \mathrm{hr}$. The number of episodes of vomiting among those who had vomited ranged from one to six in both groups between zero and two hours. This ranged from one to five (infusion group) and one to six (bolus group) between two and $24 \mathrm{hr}$. 
Table 2 Nausea and vomiting outcomes

\begin{tabular}{|c|c|c|c|c|c|}
\hline & Infusion $(n=81)$ & Bolus $(n=79)$ & $P$ value & RR & $95 \% \mathrm{CI}$ \\
\hline Intraoperative nausea & $37(46 \%)$ & $59(75 \%)$ & $<0.001$ & 0.61 & 0.47 to 0.80 \\
\hline Intraoperative vomiting & $8(10 \%)$ & $15(19 \%)$ & 0.11 & 0.52 & 0.23 to 1.16 \\
\hline Intraoperative antiemetic & $21(26 \%)$ & $33(42 \%)$ & 0.04 & 0.62 & 0.40 to 0.97 \\
\hline IONV & $37(46 \%)$ & $59(75 \%)$ & $<0.001$ & 0.61 & 0.47 to 0.80 \\
\hline Hypotension-associated IONV & $5 / 37(13 \%)$ & $32 / 59(54 \%)$ & $<0.001$ & 0.25 & 0.11 to 0.58 \\
\hline Worst intraoperative nausea score & $0[0-5]$ & $4[0-7]$ & 0.002 & & \\
\hline Worst intraoperative pruritus score & $1[0-5]$ & $0[0-3]$ & 0.048 & & \\
\hline Patients very satisfied with IONV control & $73 / 80(91 \%)$ & $67 / 78(86 \%)$ & 0.29 & 1.06 & 0.95 to 1.19 \\
\hline $0-2 \mathrm{hr}$ nausea & $26(32 \%)$ & $29(37 \%)$ & 0.55 & 0.87 & 0.57 to 1.34 \\
\hline $0-2 \mathrm{hr}$ worst nausea score & $0[0-2]$ & $0[0-4]$ & 0.33 & & \\
\hline $0-2 \mathrm{hr}$ vomiting & $9(11 \%)$ & $20(25 \%)$ & 0.02 & 0.44 & 0.21 to 0.90 \\
\hline $0-2 \mathrm{hr}$ need for antiemetic & $15(19 \%)$ & $20(25 \%)$ & 0.31 & 0.73 & 0.40 to 1.32 \\
\hline 2-24 hr nausea & $28(35 \%)$ & $26(33 \%)$ & 0.83 & 1.05 & 0.68 to 1.62 \\
\hline $2-24 \mathrm{hr}$ worst nausea score & $0[0-5]$ & $0[0-5]$ & 0.99 & & \\
\hline 2-24 hr vomiting & $15(19 \%)$ & $14(18 \%)$ & 0.90 & 1.04 & 0.54 to 2.02 \\
\hline 2-24 hr need for antiemetic & $20(25 \%)$ & $19(24 \%)$ & 0.89 & 1.03 & 0.59 to 1.77 \\
\hline
\end{tabular}

$\mathrm{CI}=95 \%$ confidence interval; $\mathrm{IONV}=$ intraoperative nausea and/or vomiting; $\mathrm{RR}=$ relative risk. Data are median [interquartile range], $n(\%)$ or $n / \mathrm{N}(\%)$

Table 3 Hemodynamic data

\begin{tabular}{|c|c|c|c|c|c|}
\hline & Infusion $(n=81)$ & Bolus $(n=79)$ & $P$ value & $\mathrm{RR}$ & $95 \% \mathrm{CI}$ \\
\hline Number of interventions per patient & $1[0-2]$ & $3[2-6]$ & $<0.001$ & & \\
\hline Pre-delivery hypotension & $22(27 \%)$ & $59(75 \%)$ & $<0.001$ & 0.36 & 0.25 to 0.53 \\
\hline Post-delivery hypotension & $6(7 \%)$ & $34(43 \%)$ & $<0.001$ & 0.17 & 0.08 to 0.39 \\
\hline Number of hypotensive episodes per patient & $0[0-1]$ & $3[1-4]$ & $<0.001$ & & \\
\hline Pre-delivery hypertension & $36(44 \%)$ & $17(21 \%)$ & 0.002 & 2.07 & 1.27 to 3.36 \\
\hline Post-delivery hypertension & $11(13 \%)$ & $6(7 \%)$ & 0.22 & 1.79 & 0.69 to 4.60 \\
\hline Number of hypertensive episodes per patient & $1[0-2]$ & $0[0-1]$ & 0.001 & & \\
\hline Bradycardia $\left(\mathrm{HR}<50\right.$ beats $\left.\cdot \mathrm{min}^{-1}\right)$ & $9(11 \%)$ & $3(4 \%)$ & 0.08 & 2.93 & 0.82 to 10.4 \\
\hline Received glycopyrrolate & $6(7 \%)$ & $2(3 \%)$ & 0.16 & 2.93 & 0.61 to 14.1 \\
\hline
\end{tabular}

$\mathrm{CI}=95 \%$ confidence interval; $\mathrm{HR}=$ heart rate; $\mathrm{RR}=$ relative risk. Data are median [interquartile range] or $n(\%)$

Hemodynamic data are presented in Table 3. Bolus administration of phenylephrine was associated with more median [IQR] interventions to maintain target blood pressure compared to infusion of phenylephrine (3 [2-6] interventions vs 1 [0-2] intervention, respectively; $P<$ 0.001 ). The incidence of pre-delivery hypotension (RR, $0.36 ; 95 \% \mathrm{CI}, 0.25$ to $0.53 ; P<0.001)$ and post-delivery hypotension (RR, $0.17 ; 95 \% \mathrm{CI}, 0.08$ to $0.39 ; P<0.001$ ) and the median [IQR] number of hypotensive episodes were significantly greater in the bolus group compared to the infusion group (0 [0-1] vs 3 [1-4]; $P<0.001)$. However, pre-delivery reactive hypertension was more common (RR, 2.07; 95\% CI, 1.27 to $3.36 ; P=0.002)$ and median [IQR] hypertensive episodes were more frequent in the infusion group (1 [0-2] vs 0 [0-1], $P=0.001)$. There were no significant differences in the incidence of postdelivery hypertension or bradycardia between groups. Similarly, there was no difference in the number of patients who required glycopyrrolate administration.

When analyzed by site, there were no significant differences in the incidence of IONV, need for rescue antiemetics or hypotension between the two sites (Table 4). However, there were significant differences between the two sites in surgical duration, total fluids administered, estimated blood loss, and uterine exteriorization. The 
Table 4 Institutional differences

\begin{tabular}{|c|c|c|c|}
\hline & Duke $(n=50)$ & IWK $(n=110)$ & $P$ value \\
\hline Duration of surgery (min) & $67(23)$ & $51(18)$ & $<0.001$ \\
\hline Repeat Cesarean delivery & $39(78 \%)$ & $94(85 \%)$ & 0.24 \\
\hline Volume of lactated Ringer's solution administered (mL) & $2539(424)$ & $1843(364)$ & $<0.001$ \\
\hline Estimated blood loss (mL) & $868(248)(n=49)$ & $655(188)(n=105)$ & $<0.001$ \\
\hline Total phenylephrine used (micrograms) & $1233(1333)$ & $1258(1124)$ & 0.90 \\
\hline Uterus exteriorized & $44(88 \%)$ & $25(23 \%)$ & $<0.001$ \\
\hline Hypotension & $31(62 \%)$ & $53(48 \%)$ & 0.11 \\
\hline Intraoperative nausea & $25(50 \%)$ & $71(65 \%)$ & 0.09 \\
\hline Intraoperative vomiting & $8(16 \%)$ & $15(14 \%)$ & 0.69 \\
\hline IONV & $25(50 \%)$ & $71(65 \%)$ & 0.08 \\
\hline Antiemetic & $19(38 \%)$ & $35(32 \%)$ & 0.44 \\
\hline
\end{tabular}

$\mathrm{IONV}=$ intraoperative nausea and/or vomiting. Data are mean (standard deviation), or $n(\%)$

proportion of participants with a repeat $\mathrm{CD}$ and the total phenylephrine administered did not differ between sites.

\section{Discussion}

In this multicentre, double-blinded, randomized, placebocontrolled trial, a prophylactic phenylephrine infusion was superior to rescue bolus dosing of phenylephrine for the prevention of intraoperative nausea in obese parturients undergoing elective $\mathrm{CD}$ under spinal anesthesia.

Our findings are consistent with previous studies of nonobese parturients that demonstrated a lower incidence of IONV with prophylactic phenylephrine infusions compared to the bolus dosing strategy. ${ }^{4,5,19}$ These studies, however, did not include obese parturients and were not powered for IONV as their primary outcome. In studies that compared different prophylactic doses of phenylephrine for prevention of spinal-induced hypotension during $\mathrm{CD}$, the incidence of IONV was least in groups that used the largest phenylephrine doses to maintain blood pressure close to $100 \%$ of baseline. ${ }^{20-22}$ Despite our results being consistent with other studies of phenylephrine prophylaxis, tighter control of intraoperative blood pressure, i.e., within $100 \%$ of baseline, may have improved results and reduced wide fluctuations in blood pressure. ${ }^{23}$

We recognize that the pathophysiology of IONV in the setting of CD is multifactorial and that hypotension is an important, but not the only contributing factor. Despite a marked reduction in pre-delivery hypotension and number of hypotensive episodes, the incidence of IONV among obese parturients treated with prophylactic phenylephrine infusion remained $46 \%$ and is comparable to the incidence of IONV reported by Allen et al. and Habib et al. in parturients with lower BMI. ${ }^{18,24}$ Both studies continued data collection for ten minutes after delivery as we have done here, while many studies stopped data collection at uterine incision or at delivery and might have therefore reported a lower incidence of IONV. One contributing factor to IONV is the exteriorization of the uterus following delivery. ${ }^{24,25}$ Interestingly, in this study, while there was a significant difference in exteriorization rates between the two sites, this did not translate to differences in IONV. It was widely believed that uterine exteriorization increased nausea and vomiting intraoperatively. A recent systematic review has found there is no significant difference in IONV when exteriorized $v s$ in situ $\mathrm{CD}$ is performed. $^{26}$

In this study, the prophylactic phenylephrine infusion was superior to rescue phenylephrine boluses at reducing the incidence of hypotension in obese parturients. This is consistent with the findings of studies in non-obese parturients. ${ }^{4,5,19}$ However, the incidence of hypotension of $27 \%$ in the infusion group in this study was higher than the incidence of $16-19 \%$ that we found in a previous study $^{24}$ using similar hyperbaric bupivacaine dosing and a comparable infusion technique in parturients of lower BMI. This suggests that sympathectomy might have been more extensive in this group of obese parturients included in the current study. ${ }^{9,11,27}$ Previous studies have however suggested that there was no significant difference in the ED95 for hyperbaric bupivacaine requirements for $\mathrm{CD}$ between obese and non-obese parturients, but there was significant variability in dose requirements among obese parturients. ${ }^{7,15,28}$ With our standard dosing of $12 \mathrm{mg}$ used in this study, the median height of the block was T4, but there was variability with some blocks extending as high as T1. Nonetheless, the incidence of hypotension of $75 \%$ in the boluses group was comparable to the incidence of $80 \%$ that we found in a smaller cohort of 20 patients in a 
previous study using the same dose of hyperbaric bupivacaine. $^{18}$

The infusion strategy was associated with fewer provider interventions to maintain baseline blood pressure within our target range compared to the bolus group, which again is comparable to that observed in parturients with lower BMI. ${ }^{5,18}$ This reduction in interventions may allow for less burden for the anesthesiologist providing care, which is particularly desirable when caring for an awake parturient who might need constant communication and reassurance. While we would have anticipated higher patient satisfaction scores with improved intraoperative nausea control in the infusion group, we saw no differences in patient satisfaction scores between the two groups. This may have been due to prompt treatment of hypotension and nausea.

Interestingly, we also found a reduction in early postoperative vomiting in the phenylephrine infusion group, while intraoperative vomiting was not significantly reduced compared to the bolus group. The reason for this reduction is unclear, since we expect that phenylephrine infusion would mainly reduce hypotension-related emetic episodes. It is possible that release of emetogenic substances such as serotonin from the gut in response to intraoperative hypotension could have contributed to this early postoperative vomiting. Near the end of our study, we introduced the Alexis $\left({ }^{\circledR}\right)$ O C-Section Retractor at our centre. We do not know if this device was used on our participants. The Alexis( $\left({ }^{\circ}\right) \mathrm{O}$ C-Section Retractor may reduce the incidence of $\mathrm{IONV}$, but there is no evidence to currently suggest this retractor might reduce IONV.

To our knowledge, this is the first double-blinded, randomized, placebo-controlled trial to demonstrate a benefit of phenylephrine infusion $v s$ bolus dosing on the incidence of IONV in obese parturients undergoing CD under spinal anesthesia.

In conclusion, we found a lower incidence of IONV with prophylactic phenylephrine infusions compared to rescue treatment of hypotension with phenylephrine boluses in obese parturients undergoing CD under spinal anesthesia. Future studies are needed to evaluate the impact of prophylactic antiemetics in addition to prophylactic phenylephrine infusions in this population.

Acknowledgements Ronald B. George would like to acknowledge the support of the Canadian Anesthesiologists' Society Career Scientist Award. Jennifer E. Dominguez is supported by NIH 5T32GM008600-20, and Terrence K. Allen is supported by the National Center for Advancing Translational Sciences of the National Institutes of Health under Award Number KL2TR001115. The content of this manuscript is solely the responsibility of the authors and does not necessarily represent the official views of the National Institutes of Health.

Conflicts of interest None declared.
Editorial responsibility This submission was handled by Dr. Philip M. Jones, Associate Editor, Canadian Journal of Anesthesia.

Author contribution Ronald B. George contributed to the study design, data collection, data analysis and interpretation, drafting the article, critical revision of the article, and final approval of the version to be published. Dolores M. McKeen contributed to the study design, data collection, critical revision of the article, and final approval of the version to be published. Jennifer E. Dominguez contributed to data collection, drafting the article, critical revision of the article, and final approval of the version to be published. Terrence $K$. Allen contributed to the study design, data collection, critical revision of the article, and final approval of the version to be published. Patricia A. Doyle contributed to data analysis and interpretation, drafting the article, and final approval of the version to be published. Ashraf $S$. Habib contributed to the study design, data collection, data analysis and interpretation, critical revision of the article, and final approval of the version to be published.

Funding This work was supported by an IWK Health Centre Category B grant.

\section{References}

1. Klohr S, Roth R, Hofmann T, Rossaint R, Heesen M. Definitions of hypotension after spinal anaesthesia for caesarean section: literature search and application to parturients. Acta Anaesthesiol Scand 2010; 54: 909-21.

2. Datta S, Alper MH, Ostheimer GW, Weiss JB. Method of ephedrine administration and nausea and hypotension during spinal anesthesia for cesarean section. Anesthesiology 1982; 56: 68-70.

3. Racke $K$, Schworer H. Regulation of serotonin release from the intestinal mucosa. Pharmacol Res 1991; 23: 13-25.

4. Ngan Kee WD, Khaw KS, Ng FF, Lee BB. Prophylactic phenylephrine infusion for preventing hypotension during spinal anesthesia for cesarean delivery. Anesth Analg 2004; 98: 815-21.

5. Siddik-Sayyid SM, Taha SK, Kanazi GE, Aouad MT. A randomized controlled trial of variable rate phenylephrine infusion with rescue phenylephrine boluses versus rescue boluses alone on physician interventions during spinal anesthesia for elective cesarean delivery. Anesth Analg 2014; 118: 611-8.

6. Ogden CL, Carroll MD, Fryar CD, Flegal KM. Prevalence of obesity among adults and youth: United States, 2011-2014. NCHS Data Brief, No 219. Hyattsville, MD: National Center for Health Statistics; 2015. Available from URL: http://c. ymcdn.com/sites/www.acutept.org/resource/resmgr/Critical_Edg Email/0216-prevalence-of-obesity.pdf (accessed November 2017).

7. Carvalho B, Collins J, Drover DR, Atkinson Ralls L, Riley ET. $\mathrm{ED}(50)$ and $\mathrm{ED}(95)$ of intrathecal bupivacaine in morbidly obese patients undergoing cesarean delivery. Anesthesiology 2011; 114 : 529-35.

8. Pace $N L$. Intrathecal dosing for cesarean delivery in obese and nonobese patients. Anesthesiology 2011; 115: 899-900.

9. Soens MA, Birnbach DJ, Ranasinghe JS, van Zundert A. Obstetric anesthesia for the obese and morbidly obese patient: an ounce of prevention is worth more than a pound of treatment. Acta Anaesthesiol Scand 2008; 52: 6-19.

10. Vasan RS. Cardiac function and obesity. Heart 2003; 89: 1127-9. 
11. Brodsky JB, Lemmens HJ. Regional anesthesia and obesity. Obes Surg 2007; 17: 1146-9.

12. Habib A, D'Angelo R. Obesity. In: Chestnut DH, Wong CA, Tsen LC, Ngan Kee WD, Beilin Y, Mhyre J, editors. Chestnut's Obstetric Anesthesia: Principles and Practice. 5th ed. Philadelphia, PA: Elsevier/Saunders; 2014. p. 1142-3.

13. Saravanakumar K, Rao SG, Cooper GM. Obesity and obstetric anaesthesia. Anaesthesia 2006; 61: 36-48.

14. Lamon AM, Habib AS. Managing anesthesia for cesarean section in obese patients: current perspectives. Local Reg Anesth 2016; 9: 45-57.

15. Lee $Y$, Balki M, Parkes $R$, Carvalho JC. Dose requirement of intrathecal bupivacaine for cesarean delivery is similar in obese and normal weight women (Portuguese). Rev Bras Anestesiol 2009; 59: 674-83.

16. Health Canada. Canadian Guidelines for Body Weight Classification in Adults - Quick Reference Tool for Professionals 2003. Available from URL: https://www.canada.ca/content/dam/ hc-sc/migration/hc-sc/fn-an/alt_formats/hpfb-dgpsa/pdf/nutrition/ cg_quick_ref-ldc_rapide_ref-eng.pdf (accessed November 2017).

17. Lamon AM, Einhorn LM, Cooter M, Habib AS. The impact of body mass index on the risk of high spinal block in parturients undergoing cesarean delivery: a retrospective cohort study. J Anesth 2017; 31: 552-8.

18. Allen TK, George RB, White WD, Muir HA, Habib AS. A doubleblind, placebo-controlled trial of four fixed rate infusion regimens of phenylephrine for hemodynamic support during spinal anesthesia for cesarean delivery. Anesth Analg 2010; 111: 1221-9.

19. das Neves JF. Monteiro GA, de Almeida JR, Sant'Anna RS, Bonin $H B$, Macedo $C F$. Phenylephrine for blood pressure control in elective cesarean section: therapeutic versus prophylactic doses (Portuguese). Rev Bras Anestesiol 2010; 60: 391-8.

20. Ngan Kee WD, Khaw KS, Ng FF. Comparison of phenylephrine infusion regimens for maintaining maternal blood pressure during spinal anaesthesia for caesarean section. Br J Anaesth 2004; 92: 469-74.

21. Ngan Kee WD, Khaw KS, Ng FF. Prevention of hypotension during spinal anesthesia for cesarean delivery: an effective technique using combination phenylephrine infusion and crystalloid cohydration. Anesthesiology 2005; 103: 744-50.

22. Stewart A, Fernando R, McDonald S, Hignett $R$, Jones T, Columb $M$. The dose-dependent effects of phenylephrine for elective cesarean delivery under spinal anesthesia. Anesth Analg 2010; 111: 1230-7.

23. Ngan Kee WD. Phenylephrine infusions for maintaining blood pressure during spinal anesthesia for cesarean delivery: finding the shoe that fits. Anesth Analg 2014; 118: 496-8.

24. Habib AS, George RB, McKeen DM, et al. Antiemetics added to phenylephrine infusion during cesarean delivery: a randomized controlled trial. Obstet Gynecol 2013; 121: 615-23.

25. Siddiqui M, Goldszmidt E, Fallah S, Kingdom J, Windrim R, Carvalho JC. Complications of exteriorized compared with in situ uterine repair at cesarean delivery under spinal anesthesia: a randomized controlled trial. Obstet Gynecol 2007; 110: 570-5.

26. Zaphiratos V, George RB, Boyd CJ, Habib AS. Uterine exteriorization compared with in situ repair for cesarean delivery: a systematic review and meta-analysis. Can J Anesth 2015; 62: 1209-20.

27. Roofthooft E. Anesthesia for the morbidly obese parturient. Curr Opin Anaesthesiol 2009; 22: 341-6.

28. Ginosar Y, Mirikatani E, Drover DR, Cohen SE, Riley ET. ED50 and ED95 of intrathecal hyperbaric bupivacaine coadministered with opioids for cesarean delivery. Anesthesiology 2004; 100 : 676-82. 